\title{
Agent Modeling of Information Assurance
}

\author{
Robert Nehmer, Oakland University, USA
}

\begin{abstract}
This paper presents a conceptual overview of a simulation experiment involving CPAs and assurance services. In this paper, a simplified situation is developed in which some agents are producers of information and other agents are consumers of information. This type of situation actually models capital markets well, where companies are producing annual reports (information production) and investors are evaluating the reports prior to making investment decisions (information consumption). The CPAgent in the model acts in one of two modes. In the first mode, it can increase the reliability of information production and thereby increase information efficiency. In the second mode, it can promote the relevance of the information to the information consumer, thereby increasing information effectiveness. The model operationalizes continuous auditing through learning. The model is given some additional theoretical interest by appealing to Habermas' Communicative Action Theory. In this theory, communication between individuals (agents) is seen as being influenced by four validities: performance, sincerity, legitimacy, and truth. In the model, performance and sincerity are affected by the CPAgent's working with information producers. Legitimacy and truth are two validities that the CPAgent can influence on the information consumer's side. The paper presents results of simulations run using the above model. Factors that were varied include the information loss function from period to period and the costs of the CPAgents services. Service costs were differentiated between information production assurance costs and information consumption assurance costs. Reputation affects for all three types of agents were also varied. The results indicate a stable model under conditions which are both interesting and realistic. The final section of the paper presents an extension which addresses modeling agents as both information producers and consumers and CPAgents as having aptitude in both efficient information production and effective information consumption activities.
\end{abstract}

Keywords: Information assurance, software agents, economic simulation

\section{INTRODUCTION}

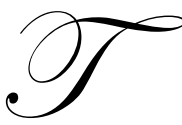

he American Institute of Certified Public Accountants (AICPA) has been involved for the last decade in the development of some major new classes of services called assurance services. These services can be understood as a generalization of the traditional audit service which attests as to the fairness of the financial statements. Assurance services will assure the information consumer of the quality of the information signal sent from any business information source. The problem has been modeled by the AICPA as being composed of the following components: business risk, decision relevance, and systems reliability.

Business risk has been defined as "the threat that an event or action will adversely affect an organization's ability to achieve its business objectives and execute its strategies successfully" (The Economist Intelligence Unit 1995). It can be decomposed into the following parts: strategic environment risks, operating environment risks, and information risks. Information technologies have a huge impact on risk by flattening the organizational hierarchy and empowering employees thereby making many traditional management control techniques obsolete.

Decision relevance is addressed in the model by shifting the focus of analysis from institutional concerns affecting comparability issues to a decision maker centered approach. This approach consists of environmental scanning, definition/construction of measures, sourcing/finding data, and sensitivity analysis. This effectively moves the level of analysis from the public domain (financial statements) to the private domain (decision maker level). 
Information technology developments have made enormous processing power available at very low cost. Competitive pressures require organizations to exploit these technologies. Organizations can respond quickly to market threats and opportunities only if they have reliable information available in a timely manner. This information is provided by systems which are affected by continuous round-the-clock processing, greater accessibility and greater dependence on enterprise-wide information systems in flatter organizations, sharing of critical business information with strategic partners, and reliance on packaged systems. Management and owners are increasingly concerned with the reliability of the data produced by these systems. This data needs to be timely, accurate, and accessible.

\section{NATURE OF ASSURANCE SERVICES}

Systems quality assurance provides users with assurance that a system has been designed and operated to produce reliable data. System assurance involves testing the integrity of an information system." (AICPA, Assurance Services webpage) The solution to this situation is to implement a reliability-by-design model.

This paper presents a conceptual overview of a simulation experiment involving CPAs and assurance services. In this paper, a simplified situation is developed in which some agents are producers of information and other agents are consumers of information. This type of situation actually models capital markets well, where companies are producing annual reports (information production) and investors are evaluating the reports prior to making investment decisions (information consumption). The CPAgent in the model acts in one of two modes. In the first mode, it can increase the reliability of information production and thereby increase information efficiency. In the second mode, it can promote the relevance of the information to the information consumer, thereby increasing information effectiveness. The model operationalizes continuous auditing through learning.

The model is given some additional theoretical interest by appealing to Habermas' Communicative Action Theory. In this theory, communication between individuals (agents) is seen as being influenced by four validities: performance, sincerity, legitimacy, and truth. Performance validity refers to the technical construction of an utterance, in this case, to the construction of an informational signal by an information producing agent. Sincerity refers to fit of the signal to the information environment into which it is communicated, that is, that the signal is complete and understandable. In the model, these two validities are affected by CPAgent's working with information producers. A signal is considered legitimate in Habermas' theory if the receiver of the information believes the sender has the social standing to send the signal. This is akin to investors recognizing valid investments. Truth validity refers to the perceived truth of the information signal by its consumer. Legitimacy and truth are two validities that the CPAgent can influence on the information consumer's side.

The paper presents results of simulations run using the above model. Factors that were varied include the information loss function from period to period and the costs of the CPAgents services. Service costs were differentiated between information production assurance costs and information consumption assurance costs. Reputation affects for all three types of agents were also varied. The results indicate a stable model under conditions which are both interesting and realistic. The final section of the paper presents an extension which addresses modeling agents as both information producers and consumers and CPAgents as having aptitude in both efficient information production and effective information consumption activities.

\section{SOFTWARE AGENTS}

The Internet is a storehouse of information. There is so much information many people can not handle all of it. They need the information, but are unable to process it at the speed it is given to them. This is the purpose of intelligent agents. They have been developed to assist people and often act on their behalf. The software allows people to delegate work. The agents can act as your personal assistant just like a human assistant. They can automate repetitive task, remember things you forgot, intelligently summarize complex data, learn from you, and even make recommendations to you. (Greenstein and Vasarhelyi, 412).

In the area of agents there are two types of agents. One is a single agent only able to interface with humans, and the other is a multi-agent, which are able to communicate between other agents. The two agents are able to 
cooperate between one another through directives. This form of intelligent agent software is the most beneficial to commerce on the Internet. There are many software products on the market now that allows agent software to communicate with on another. Some software is built around the notion to mediate between two-agent software so that the two agents are able to communicate with one another. One of these products is called GINA. GINA is designed to link two-agent software together so they can communicate with one another. This type of technology is essential to the commerce on the Internet. Many times the consumer on the Internet is bombarded with a lot of information and will frustrate the consumer. The solution to this problem is through the use of agents. Agents will perform many of the repetitive tasks for the consumer and will actively gather information from the user. This information will be used to respond by making shopping experiences on the Internet less time consuming, and a more enjoyable experience (www.sgi.com).

As more people use the web for commerce the need for agent software is evident. However, there are some problems with developing stand alone agent software. If there are several different software applications they will not be able to communicate with one another. Many agents are single-agent software and are not designed to communicate with different agents. There are also many-multi agents that are developed without standards for communication between them. This leaves room for a new type of agent software that allows two agents to communicate with one another. The software is nonbiased between single-agent software and multi-agent software.

There are several software applications being developed, one is by the University of Carnegie Mellon Robotics Institute. They have developed an infrastructure of reusable agents called RETSINA. The RESTINA infrastructure is built around the use of these middle agents. They are used to bridge heterogeneous agent types and architectures and allow them to interpret successfully. The RESTINA agent has four reusable modules for communicating, planning, scheduling, and monitoring the execution of task and request from other agents. This research software is being used to increase the efficiency of management and information problems, such as joint mission planning, personal calendar management, web tour guides and digital assistants, and many other supporting software assistants (www.cs.cmu.edu/ softagents/). The middle agents that are on the Internet are identified as matchmakers (yellow page service), brokers, billboards, etc. The process works were a provider agent advertises their capabilities to middle agents. Middle agents then store these advertisements, and a requester asks middle agent whether it knows of providers with the desired capabilities. The middle agent is seen as the broker between the producer and the consumer. They match the request against the stored advertisements and give the consumer the results. The ability for single-agent software to communicate is very complicated and generally does not understand one another. This is the reason new agents are needed to mediate between single and multi-agents.

There are many software developments that are allowing the communication between agents through middle agents. One of such developments is a software middle agent called LARKS. This agent was developed through the research efforts of the University of Carnegie Mellon Robotics Institute. This software is incorporated with the infrastructure of RESTINA mentioned earlier. The agent itself structures many types of multi-agent platforms to reinforce learning. The agent is a self-interested entity and behaves to achieve maximum reward in the range of its knowledge of the environment it operates in. the agent is not equipped with prior knowledge. This gives rise to a type of reinforced learning for the agent through algorithms. The University of Carnegie Mellon Robotics Institute has developed one of many algorithms to approach this problem. They have developed a method called the Profit Sharing Plan. This approach of learning is different than others. It does not assume an agent's state in advance. The PSP algorithm allows an autonomous agent to learn progressively without any instruction and with delayed rewards. This is important because middle agents have performance characteristics of privacy, robustness, and adaptability. They are in a position of changing information and the way the user view and use this information. The middle agent must be able to adapt to the environment it is currently in by gathering information around it and interpolating it (www.cs.cmu.edu/ softagents/).

\section{CONCEPTUAL MODEL}

The accounting profession has recently been moving towards the acceptance of the information, rather than dollar, model. This move has been accompanied by both a movement from information reliability to information relevance and a movement from tests of management assertions to systems assurance (reliability). We can consider systems reliability to focus on the information production aspects of an information economy. Systems reliability 
assurance includes the COSO internal control framework, information reliability for managers, and information reliability for external parties. As we move forward, it is also coming to include continuous auditing with software agents and the specification of the information model of the firm to such detail that an information dual is created (emulation). The information consumption side of the information economy must take into account the information needs of decision makers including information on the decision model used (metadata), information on defining business objectives and information needs, information on designing actions, information on measuring model performance (the effectiveness side), information on designing and developing new decision making models and environmental scanning including finding valuable data in the environment and measuring new data items. The overall picture of this information economy is shown in Figures 1 and 2.

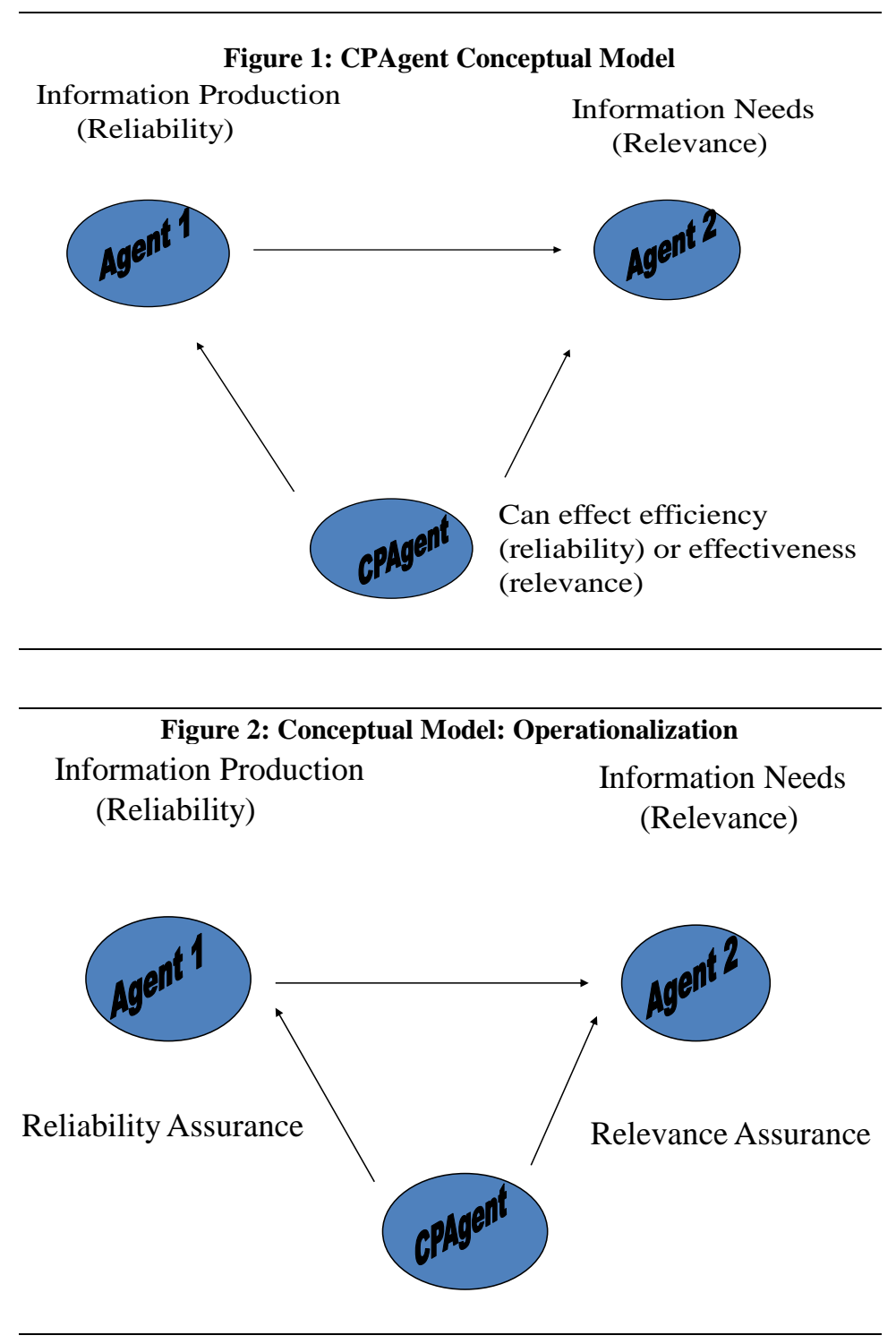

\section{COMMUNICATIVE ACTION THEORY}

Habermas proposes a theory of communicative action (i.e., 1975, 1984, 1987) within which he formulates a framework for understanding the dynamics of capitalist societies. Briefly, the theory of communicative action attempts to ground action in the context of discourse, the central medium of which is language, through the 
authentication of validity claims (truth, sincerity, and correctness). Central to his position is the proposition that for action, motivated by speech acts (Searle, 1969), to be undertaken the validity claims must be satisfied or that these claims could be satisfied if the speaker were called upon to do so. In setting forth this theory, Habermas attempts to engage rationality in carrying out communicative action as opposed to strictly instrumental or "strategic" action. He does so in an attempt to bring to bear the rationalization of modern society in providing emancipatory opportunities. In the following discussion, we attempt to reinterpret society within this critical theoretic. However, due the inherent inability to totally specify (rationalize) work, the scientific management is crushed under the weight of the "expertise" required in specification and coordination. Spiraling indirect costs are a reflection of the demand for technology to solve the problems created by technology.

According to Habermas, consensus must precede communication. This consensus is based on the validity claims of truth, legitimacy, veracity, and comprehensibility. When all four of these claims are not met, the communication must precede on the level of discourse. L\&J's entailments are categorized by subcategorization relationships. Thus, information may be transmitted under any speaking situation through the transference or recognition of entailments. Habermas' theory seems to miss those situations where we agree to disagree, that is, those times when one enters into a discourse and comes away with (some) information about another person or that person's point of view.

In order to operationalize some of Habermas' theorizing, this paper concentrates on the linguistic, as opposed to the socio-economic, aspects of the theory of communicative action. As previously discussed, Habermas envisions three types of action. The first type is instrumental action which is an action oriented to success in a nonsocial situation. The second type is strategic action which is an action oriented to success in a social setting. The last type is communicative action which is action oriented to reaching understanding in a social situation. Habermas terms all language which occurs while accomplishing these actions as discourse except for a single exception. Language which is used to accomplish communicative action is termed communication.

Habermas says that all communication must be valid (correct) in four ways. First, it must be performed correctly to be comprehensible. This validity claim is often assumed to be true and is called performance. Second, it must be socially valid, that is, legitimate. This claim is based on the social position of the person who is communicating. That person must be in a legitimate social position to perform the specific speech act. Consider the social position one needs to legitimately close a university for a snow emergency. The third validity claim is that of truth, that is, that the statement made is true. The last claim is that the utterance is said sincerely, without irony or malice.

\section{CONCEPTUAL MODEL: OPERATIONALIZATION}

Figure 3 Operationalization of the Conceptual Model

Information Production:
Performance

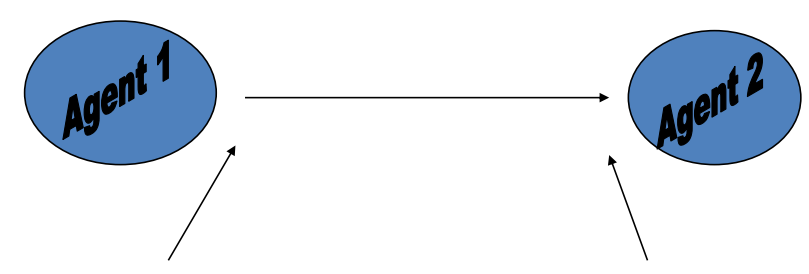

Information Transmission: Sincerity

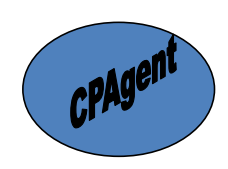

Information Reception: Legitimacy 
Figure 3 shows the layout of the conceptual model in graphical form. There are three agent classes. Information producing agents (Agent 1) produce information for information consuming agents (Agent 2). CPAgents can influence the transmission of information from producers to consumers in two ways. First, they can act on the flow from the producers to the consumers, affecting the performance and sincerity of the communication. Secondly, they can influence the information's reception by the consuming party and hence affect legitimacy and truth. The environment will reward reliability (performance and sincerity) and relevance (legitimacy and truth) differently in different simulations. CPAgents will increase reliability or relevance at a cost. Populations of client agents will have different needs for the two services in different simulations. CPAgents will either be reliability experts, with performance and sincerity enhancing capacities, or relevance experts with legitimacy and truth testing capacities. The environment will reward reliability and relevance differently in different simulations. CPAs will increase reliability or relevance at a cost. The population of client agents will have different needs for the two services in different simulations. CPAs will either be reliability experts, with performance and sincerity enhancing capacities, or relevance experts with legitimacy and truth testing capacities.

\section{MODEL FORMULATION}

$\mathrm{P}_{\mathrm{i}}$ represents the information producers $\left(\mathrm{P}_{1}\right)$ and information consumers $\left(\mathrm{P}_{2}\right)$. This is a 2 x 1 matrix which represents performance/validity $\left(\mathrm{P}_{1}\right)$ and sincerity/truth $\left(\mathrm{P}_{2}\right)$. Each term can take values between 0 and 1 but are strictly less than 1 with the idea that no communication is perfect. $A_{i}$ represents the CPAgent reliability experts $\left(A_{1}\right)$ and relevance experts $\left(\mathrm{A}_{2}\right)$. It is a $1 \times 2$ matrix as above which takes values between .5 and 1.5. This value range indicates the relative effectiveness of the CPAgent in affecting either reliability or relevance with 1 indicating indifference (no effect). The model is formulated from the standpoint of the communication of information from a producer to a consumer. Of course, firms are going to both produce and consume information. That aspect of the development of the model is left for an extension of the current work. Having made that point, the model treats performance and sincerity ( $P$ and $S$ ) as the model information inputs formulated as $\mathrm{I}_{\mathrm{RM}}$, information raw material a 1 $\mathrm{x} 2$ matrix of exploitable information: $\mathrm{P}$ and $\mathrm{S}$. The cost of the reliability and relevance assurance services is formulated as $\mathrm{C}_{\mathrm{i}}$, a cost vector of the CPAgents for the two services. The information producing agent is then modeled as:

$$
\mathrm{C}_{1} \mathrm{I}_{\mathrm{RM}} \mathrm{P}_{1} \mathrm{~A}_{1}=\text { SI Supply of information }
$$

The information consuming agent is similarly modeled as:

$$
\mathrm{C}_{2} \mathrm{SI} \mathrm{P}_{2} \mathrm{~A}_{2}=\text { GI Gain of information }
$$

The model also considers information entropy through a loss function:

$$
\mathrm{GI} * \text { loss function }=\mathrm{I}_{\mathrm{RM}}
$$

where this serves as a feedback loop to the information production side of the firm. As efficiency (effectiveness) increases (decreases), A's parameters are changed meaning that A will capture some of the gain (loss). This is modeled as a learning component:

$$
\begin{aligned}
& \mathrm{L}=\mathrm{A}_{\mathrm{ij}} \text { 's learning rate } \\
& \text { where } \\
& \mathrm{A}_{\mathrm{ij}}{ }^{\prime}=\left(\mathrm{L}-\left(1 /(1+\mathrm{L})^{\mathrm{n}}\right)\right) \mathrm{P} * \mathrm{i} \\
& \text { and } \mathrm{i}=\left(\mathrm{A}_{\mathrm{i} 1}+\mathrm{A}_{\mathrm{i} 2}\right) /\left(\mathrm{P}_{\mathrm{i} 1}+\mathrm{P}_{\mathrm{i} 2}\right)
\end{aligned}
$$

\section{SIMULATION RESULTS}

The following Figures show the results of some of the simulations. Note that the number of trials is shown on the $\mathrm{Y}$ axis throughout the series. The first two Figures of the series, Figures 4 and 5, show the situation when the preferences for sync with one another and then out of sync. Notice that the amount of "information" produced by the system is dampened considerably when the two parameters are out of sync. The second set of figures, Figures 6 and 7, show the difference in the economy when producers and consumers have the same preferences (Figure 6) or 
opposing preferences (Figure 7). The first economy shows an increasing production of information as the number of periods (trials) increases. The economy with opposing preferences collapses over time with the supply of $\mathrm{P}$ and $\mathrm{S}$ dwindling to near zero.

The next set of figures, Figures 8 and 9, contrast a high cost versus low cost situation. While there is information production in the high cost economy, production is on the level of three times the order of magnitude in the no cost situation (Figure 9). The final set of results, Figures 10 and 11, are contrasting scenarios where agent preferences are different, there is high efficiency but in one case greater information loss from period to period. As expected, information gains are smaller in the second case (Figure 11).

\section{FUTURE RESEARCH}

Future research plans for this project include refining the model so that each agent is explicitly an information producer and an information consumer. This is a relatively easy extension of the work presented in this paper. More model validation will also be conducted as well as consideration of the use of the simulation in policy making.

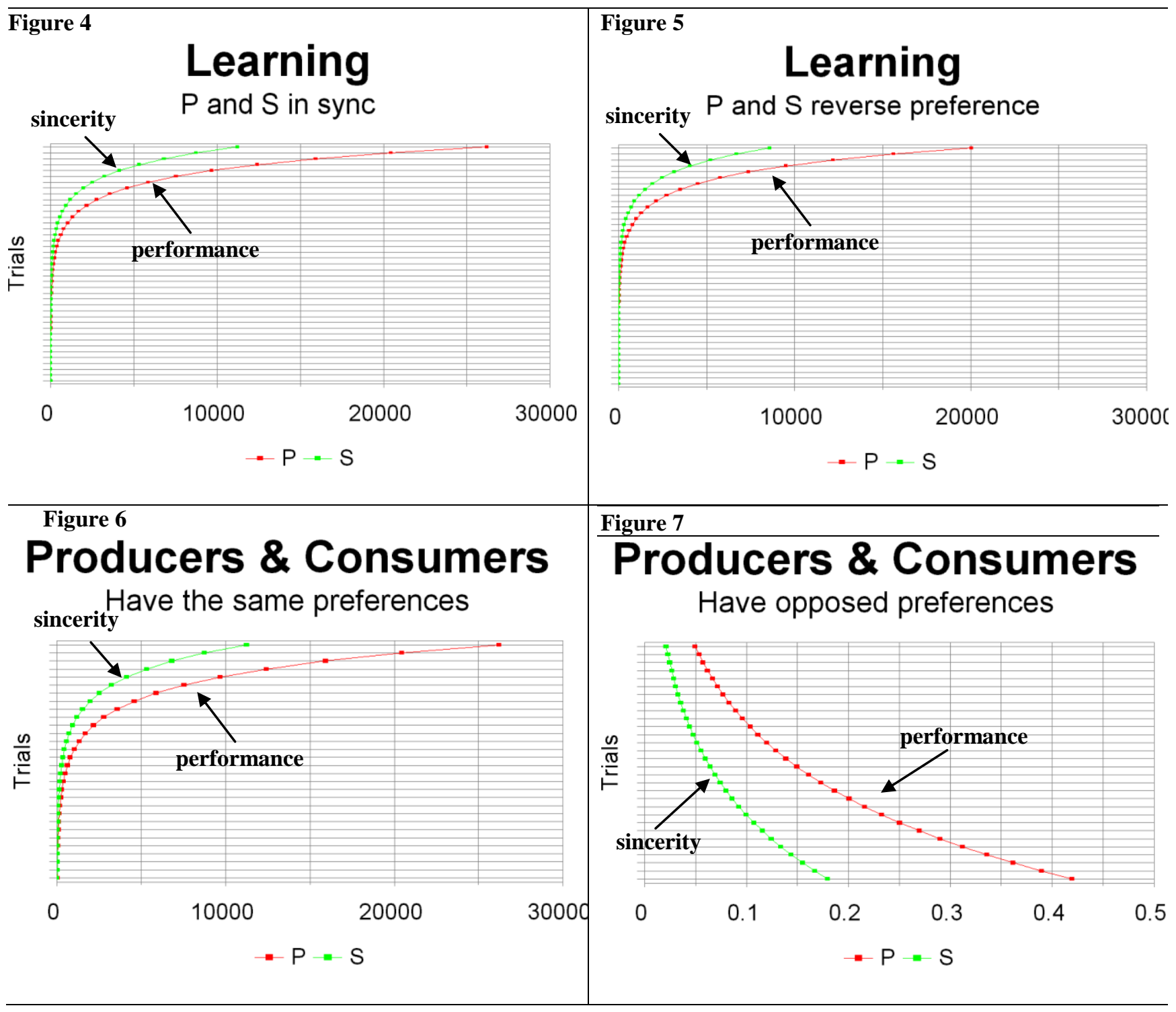




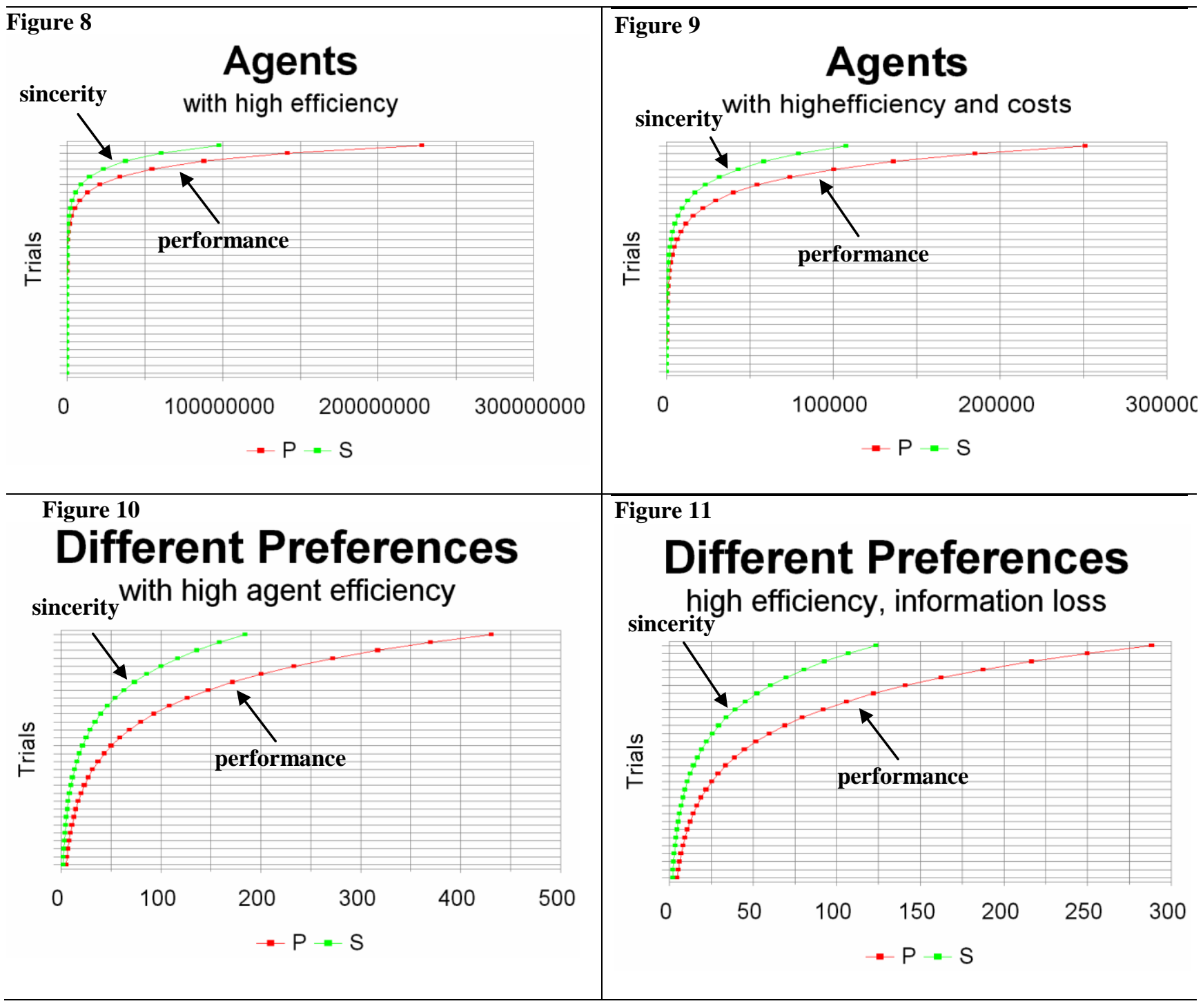

\section{REFERENCES}

1. Greenstein, Marilyn, and Miklos Vasarhelyi, Electronic Commerce: Security, Risk and Management and Control. $2^{\text {nd }}$ ed., New York: Irwin McGraw-Hill, 2002.

2. Habermas, Jurgen, Legitimation Crisis, translated by Thomas McCarthy, (Boston: Beacon Press, 1975).

3. Habermas, Jurgen, The Theory of Communicative Action: Reason and the Rationalization of Society (vol. 1), translated by Thomas McCarthy, (Boston: Beacon Press, 1984).

4. Habermas, Jurgen, The Theory of Communicative Action: Lifeworld and System: A Critique of Functionalist Reason (vol. 2), translated by Thomas McCarthy, (Boston: Beacon Press, 1987).

5. Habermas, Jurgen, The Philosophical Discourse of Modernity, translated by Frederick Lawrence, (Cambridge: MIT Press, 1987).

6. www.cs.cmu.edu/ softagents, April 15, 2000.

7. www.sgi.com, April 15, 2000. 